\title{
Common Types of Neurogenetic Disorders, A Brief Review
}

\author{
Behzad Saberi* \\ Medical Research, Esfahan, Iran \\ *Corresponding author: Behzad Saberi, Medical Research, Esfahan, Iran
}

\section{Mini Review}

There are various genetic disorders which can involve the nervous system or confined to the nervous system alone. This is a brief review on some neurogenetic disorders. Gene mutations disorders are the most common types of neurogenetic disorders. Myotonic syndromes, muscular dystrophies and motor neuron disease are some examples of these disorders. Genetic imprinting in some disorders like Prader-Willi syndrome and Angelman's syndrome can be seen. In both of these syndromes there is a disruption on a part of chromosome 15 which the autosomal genes differential expression depends on their parental origin (maternal genes disruption in Prader-Willi syndrome and father's genes disruption in Angelman's syndrome). Duplication of part of chromosome 17 which includes the peripheral myelin protein 22 gene coding, can cause some types of hereditary motor and sensory neuropathy. The patients with such disorder would develop sensory loss, distal weakness and wasting. Hereditary neuropathy with a liability to pressure palsies is an example of neurogenetic disorders with gene deletions. In this disorder there is a deletion on chromosome 17. This large deletion includes the peripheral myelin protein 22 gene coding. The affected patients can develop recurrent focal entrapment neuropathies. Mitochondrial disorders are other disorders which may result from mitochondria genome defects and nuclear-coded genes defects [1-2].

Disorders related to Trinucleotide repeat are other neurogenetic disorders. Expanded and abnormal triplet repeat in the genome can cause some disorders to appear. Friedreich's ataxia and Huntington's disease are two examples of Trinucleotide repeat disorders [3-4]. As the new genetic studying methods have been developed and is now under development, finding the genetic basis of some neurological disorders can be possible due to such developments and this causes to know the certain neurogenetic pathologies better.

\section{References}

1. Baraitser M (1990) The genetics of neurological disorders, $2^{\text {nd }}$ edn. Oxford Medical, Oxford NewYork Tokyo.

2. Mtiller U, Graeber MB, Haberhausen G, KiShler A (1994) Molecular basis and diagnosis of neurogenetic disorders. J Neurol Sci 124: 119-140.

3. Friedmann $\mathrm{T}$ (1994) Gene therapy for neurological disorders. Trends Genet 10: 210-214.

4. Suhr ST, Gage FH (1993) Gene therapy for neurologic disease. Arch Neurol 50: 1252-1268.

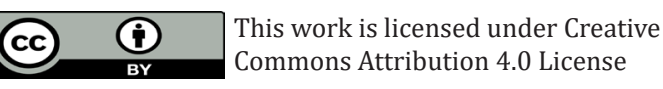

To Submit Your Article Click Here: Submit Article

DOI: 10.32474 /PAPN.2020.03.000152

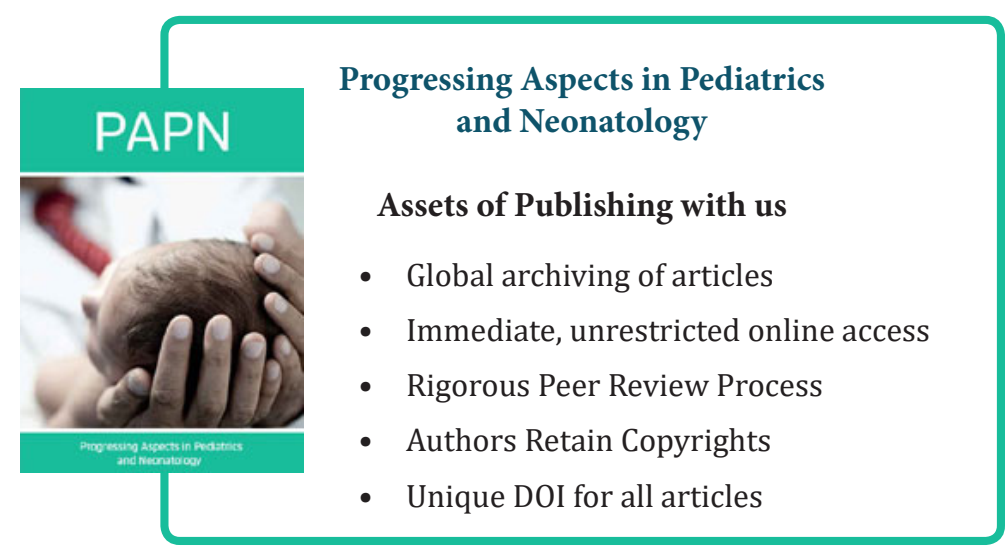

